\title{
ANALISA KEBUTUHAN INFRASTRUKTUR \\ DI KAWASAN PERBATASAN INDONESIA DAN TIMOR LESTE (DESA ASUMANU,TOHE DAN MAUMUTIN)
}

\author{
Gudino Lovato Soares $^{1)}$, Agustina Nurul Hidayati ${ }^{2)}$, Ardiyanto Maksimilianus Gai', \\ 1)2)3) Fakultas Teknik Sipil dan Perencanaan, Institut Teknologi Nasional Malang \\ email: gudinosoares7@gmail.com
}

\begin{abstract}
Abstrak
Kawasan perbatasan bernilai strategis dalam keberhasilan pembangunan nasional dan peningkataan kesejahteraan sosial ekonomi masyarakat sekitarnya. Tujuan yang ingin dicapai adalah bagaimana melihat tingkat ketersediaan sarana Infrastruktur berdasarkan standar pelayanaan minimum dan tingkat pelaynana berdasarkan persepsi masyarakat yang disaringdari kuisioner mengenai kebutuhan serta keperluan ketersediaan infrastruktur di Kawasan Perbatasan Indonesia dan Timor Leste. Hasil dari analisis menyatakan bahwa Tingkat ketersediaan infrastruktur dikawasan perbatasan dengan masing-masing jaringan dikategorikan sebagai berikut, untuk jaringan jalan dikategorikan tingkat ketersediaan sedang, jaringan air bersih dikategorikan tingkat ketersediaan tinggi, jaringan drainase dikategorikan tingkat ketersediaan rendah, jaringan limbah dikategorikan tingkat ketersediaan tinggi dan jaringan persampahan dikategorikan tingkat ketersediaan rendah. Selain itu, dikawasan perbatasan yang terdiri atas Desa Asumanu,Tohe dan Maumutin yang menjadi fokus dalam penelitian ini perlu adanya kebutuhan jalan, jembatan, telekominikasi air bersih, penggolahan limbah dan jaringan listrik.
\end{abstract}

Kata Kunci: Infrastruktur, Kawasan Perbatasan, Sarana

\begin{abstract}
The border area has strategic value in National Development and in enhancing the social and economic welfare of the surrounding community. The goal of this research is how to see the level of infrastructure resources based on minimum service standards and service levels based on community perceptions. The results of the analysis showed that the infrastructure level in the border area with each network is categorized as follows: for the road network is categorized as middle level of acceptance, clean water is categorizing as high level, drainage network is categorized as low level, waste network is categorized as high level and sanitation is categorized as low level. In addition, the border area between Asumanu and Maumutin Village, which is focus on roads, bridges, clean water, telecommunication, sanitation and electricity networks
\end{abstract}

Keywords: border area, facilities, Infrastructure.

\section{PENDAhuluan}

Pembangunan Nasional Negara Indonesia yang tujuan umumnya adalah untuk mewujudkan kesejahtran rakyat dan pemerataanya di seluruh wilayahnya.Sampai saat ini masih banyak timbul banyak masalah.salah satu masalah yang sering di jumpai adalah belum berkembangnya wilayah perbatasan antara wilayah administrasi dalam Negara Indinesia (Budiantana, 2010). Kawasan perbatasan bernilai strategis dalam keberhasilan pembangunan nasional dan peningkataan kesejahteraan sosial ekonomi masyarakat sekitarnya.Definisi kawasan perbatasan berdasarkan ketentuan umum pasal 1 angka 6 Undang-Undang No. 43 Tahun 2008 tentang Wilayah Negara (UU Wilayah Negara) yaitu merupakan bagian dari wilayah Negara yang terletak pada sisi dalam sepanjang batas wilayah Indonesia dengan Negara lain, dalam hal batas wilayah Negara di darat, kawasan perbatasan berada di kecamatan.

Pembangunan infrastruktur merupakan salah satu aspek penting dan vital untuk mempercepat proses pembangunan nasional 
maupun regional. Infrastruktur juga memegang peranan penting sebagai salah satu roda penggerak pertumbuhan ekonomi. Laju pertumbuhan ekonomidan investasi suatu negara maupun daerah tidak dapat dipisahkan dari ketersedian infrastruktur seperti transportasi, telekomunikasi, sanitasi, dan energi. Inilah yang menyebabkan pembangunan infrastruktur menjadi fondasi dari pembangunan ekonomi yang berkelanjutan. Bertambahnya infrastruktur dan perbaikannya oleh pemerintah diharapkan memacu pertumbuhan ekonomi (Suratno. 2010).

Infrastruktur juga memiliki pengaruh penting dalam peningkatan nilai konsumsi, peningkatan produktivitas tenaga kerja dan akses kepada lapangan kerja.(Atmaja 2013). Salah satu pengembangan infrastruktur yang sedang dijalankan namun belum optimal yaitu Pembangunan jalan perbatasan Sabuk Merah sektor Timur di perbatasan RI-Timor Leste yang berada di Kabupaten Belu dan Kabupaten Malaka Provinsi NTT masih terus dibangun. Jalan sepanjang 176,19 km ini pada akhir 2018 ditarget tuntas seluruhnya. "Akhir tahun 2018 direncanakan untuk jalan sudah dapat terhubung dan fungsional namun belum teraspal semua," kata Dirjen Bina Marga Kementerian PUPR Sugiyartanto saat ditemui di kantornya, Jakarta, Selasa (14/8/2018). Jalan yang dibangun sejak tahun 2015 lalu itu akan rampung dengan kondisi aspal dan tanah. Di mana $77,41 \mathrm{~km}$ di antaranya ditargetkan dengan kondisinya aspal, sementara sisanya sepanjang $98,78 \mathrm{~km}$ berupa tanah dan urukan pilihan (kerikil dan batu).(Detikfinance,2018).

\section{KAJIAN LITERATUR}

A. Definisi Infrastruktur

Infrastruktur dapat didefinisikan sebagai komponen fisik sistem yang saling terkait menyediakan layanan penting untuk memungkinkan, mempertahankan, atau meningkatkan kondisi kehidupan masyarakat. Infrastruktur fisik biasanya menyimpulkan struktur teknis seperti infrastruktur transportasi (jalan dan jaringan rel, jembatan, terowongan), Jaringan suplai air, pemanasan dan pendinginan jaringan pasokan, saluran pembuangan jaringan dan, jaringan listrik dan telekomunikasi (Adl-Zarrabi,2017).

Infrastruktur diklsifikasikan sebagai aset modal seperti utilitas, kendaraan transportasi, sistem telekomunikasi, jalan, jalan Raya, kereta api, kereta bawah tanah, lampu lalu lintas dan lampu jalan, bendungan, dinding dan gorong, sistem drainase, Bandara dan terminal bus, dan jembatan, antara lain (Skorobogatova, 2017). Selain itu, Sistem infrastruktur dapat didefinisikan sebagai fasilitas-fasilitas atau struktur-struktur dasar, peralatan-peralatan, instalasi-instalasi yang dibangun dan yang dibutuhkan untuk berfungsinya sistem sosial dan sistem ekonomi masyarakat (Warsilan,2015). Pengertian infrastruktur merujuk pada sistem fisik dalam menyediakan transportasi, pengairan, drainase, bangunan-bangunan gedung dan fasilitas publik lain seperti listrik,telekomunikasi, air bersih dsb, yang dibutuhkan untuk memenuhi kebutuhan dasar manusiadalam lingkup sosial dan ekonomi (Grigg,1988).Infrastruktur yang digunakan di perkotaan biasanya untuk memasok daya, air dan gas secara konsisten menjadi suatu kesatuan Karena masyarakat bergantung secara penuh pada infrastruktur fisik (Avritzer,2015).

\section{B. Jenis - Jenis Infrastruktur} Klasifikasi infrastruktur fisik: infrastruktur fisik dapat dibagi menjadi dua kategori utama yaitu infrastruktur permukaan dan infrastruktur bawah tanah. Infrastruktur permukaan termasuk transportasi infrastruktur, tiang untuk infrastruktur listrik dan komunikasi, pelabuhan, terminal bus dan kereta api dan Bandara. Infrastruktur bawah tanah mencakup jaringan perpipaan untuk pasokan air, panas dan gas alam, kabel listrik dan komunikasi, terowongan yang mencakup juga jaringan kereta bawah tanah (AdlZarrabi,2017).

Jenis infrastruktur transportasi: kereta api dan bus Terminal dan Stasiun; kereta bawah tanah terowongan, overpasses, jembatan; Terminal kelautan, air pelabuhan laut; Port airdroms, Bandara, Fasilitas Komunikasi, navigasi dan sistem manajemen lalu lintas; Bagian dari jalan motor, jalur kereta api dan perairan pedalaman, helikopter, lokasi pendaratan, serta bangunan, struktur, Fasilitas dan peralatan yang menyediakan pengembangan industri transportasi. Rute transportasi jalan motor, kereta api, air, dan udara (Tokunova, 2018). Fasilitas infrastruktur transportasi dasar yang 
menyediakan transportasi dan komunikasi ekonomis untuk tujuan keberhasilan pengembangan sistem ekonomi.

\section{Kawasan Perbatasan}

Kawasan perbatasan negara adalah wilayah dimana secara geografis memiliki batas secara langsung di darat dengan negara lain atau tidak langsung melalui laut lepas (Sudiar, 2017). Sedangkan menurut UndangUndang No. 43 Tahun 2008 tentang Wilayah Negara, kawasan perbatasan adalah bagian dari wilayah negara yang terletak di sisi dalam sepanjang batas wilayah Indonesia dengan negara lain, dalam hal batas wilayah negara di darat, kawasan perbatasan berada di kecamatan.

Menurut Muradi (2015) permasalahan yang menjadi kendala dalam mengefektifkan pengamanan wilayah perbatasan yaitu infrastruktur yang ada di wilayah perbatasan terbilang minim. Minimnya infrastruktur jalan dan pendukung lainnya menyulitkan Indonesia dalam melakukan pengamanan perbatasan secara luas. Konteks ini pada akhirnya membuat pengamanan wilayah perbatasan dilakukan terbatas dan cenderung seadanya.

Berdasarkan hal tersebut, salah satu hal yang paling menonjol di daerah perbatasan adalah pembangunan infrastruktur. Dengan infrastruktur yang lengkap dan bermutu baik, maka kawasan perbatasan sebagai cerminan diri dari suatu negara akan terasa semakin jelas (Sari,2019).

\section{METODE PENELITIAN}

A. Metode Pengumpulan Data

Pengolahan data menurut Arikunto (2010) meliputi kegiatan:

1. Editing

Editing adalah pengecekan atau pengoreksian data yang telah terkumpul, untuk menghilangkan kesalahan kesalahan yang terdapat pada pencatatan dilapangan dan bersifat koreksi.

2. Tabulasi

Tabulasi adalah pembuatan tabel-tabel yang berisi data yang telah diberi kode sesuai dengan analisis yang dibutuhkan. Dalam melakukan tabulasi diperlukan ketelitian agar tidak terjadi kesalahan.

3. Interpretasi Data
Pada interpretasi data peneliti memberikan penjabaran dari hasil perhitungan (tabel) dan kemudian menghubungkan dengan data - data lapangan sehingga terjadi keterkaitan antara hasil dan olahan data yang didapat di lapangan.

B. Metode Analisis

1. Analisis Ketersediaan Infrastruktutr di Kawasan Perbatasan Indonesia dan Timor Leste

Analisis Kuantitatif Untuk menjelaskan kondisi ketersediaan dan kebutuhan prasarana kawasan permukiman kumuh pada lokasi penelitian, maka pendekatan yang dilakukan adalah membandingkan ketersediaan prasarana dengan standar pelayanan minimum dan untuk mendapatkan penilaian dengan memberi bobot pada masing-masing indikator prasarana. Adapun kriteria metode untuk standar skoring yang digunakan dapat dilihat pada tabel sebagai berikut:

Tabel 1 Penilaian Skoring Infrastuktur

\begin{tabular}{cccc}
\hline No & Nilai Skor & $\begin{array}{c}\text { Presentase } \\
(\%)\end{array}$ & Kategori \\
\hline 1. & 5 & $70-100$ & Tinggi \\
\hline 2. & 3 & $40-69$ & Sedang \\
\hline 3. & 1 & $0-39$ & Rendah \\
\hline
\end{tabular}

Sumber: Dharmawansyah, 2017

2. Analisis Tingkat Pelayanan Infrastruktur di Kawasan Perbatasan

Dalam pencapaian sasaran ini, dilakukan analisis teoritical deskriptif berupa ulasan atau deskripsi indikator dan variabel sesuai dengan fakta empirik infrastruktur di kawasan perbatasan, hasilnya berupa profil kawasan berdasarkan indikator dan variabel yang diperoleh dari kuisioner dan wawancara pada beberapa responden dan melakukan observasi pada kawasan, yang kemudian dilakukan penilaian melalui proses skoring. Hasil skoring akan menunjukan nilai baik buruknya skala pelayanan dari kondisi infrastruktur yang telah diindentifikasi. Secara umum teknik dalam pemberian skor yang digunakan dalam kuesioner penelitian ini adalah teknik skala Likert. Penggunaan skala Likert menurut Sugiyono (2013:132) adalah "skala Likert digunakan untuk mengukur sikap, pendapat 
dan persepsi seseorang atau sekelompok orang tentang fenomena sosial". Berikut merupakan Skala Likert dalam penjelasan tabel 2.

Tabel 2 Skala Likert

\begin{tabular}{cl}
\hline $\begin{array}{c}\text { Skala } \\
\text { Likert }\end{array}$ & Penilaian \\
\hline 1 & Sangat Baik \\
\hline 2 & Cukup Baik \\
\hline 3 & Baik \\
\hline 4 & Kurang Baik \\
\hline 5 & Buruk adalah
\end{tabular}

eridentifikasinya konsidi infrastruktur perbatasan dan skala pelayanan infrastruktur

\section{HASIL DAN PEMBAHASAN}

\section{Hasil Analisis Ketersediaan Infrastruktur Kawasan Perbatasan}

a. Jaringan Jalan yang ada di kawasan perbatasan berdasarkan pembagian kuisioner yang dibagikan kepada penduduk local, apakah skala pelayanan yang mereka dapatkan atau terima sudah Sangat baik, cukup baik, baik, Kurang baik ataukah Buruk.
Jaringan jalan memiliki SPM 40-60m / Ha dengan lebar 2-5 m. jalan yang ada di kawasan perbatasan masing-masing memiliki panjang Desa Asumanu 352 m, Desa Tobe 245 m dan Maumutin $223 \mathrm{~m}$ dengan lebar jalan 3 meter, untuk mengetahui persentase ketersediaan panjang jalan maka digunakan metode perhitungan sebagai berikut :

Tabel 3 Hasil Analisis Ketersediaan Jaringan Jalan Kawasan Perbatasan Indonesia-Timor Leste

\begin{tabular}{|c|c|c|c|c|c|c|c|}
\hline No & Desa & $\begin{array}{l}\text { Standar } \\
\text { SPM }\end{array}$ & $\begin{array}{l}\text { Jumlah } \\
\text { Ideal }\end{array}$ & $\begin{array}{l}\text { Panjang } \\
\text { jalan } \\
(\mathrm{m}) \\
\end{array}$ & $\begin{array}{l}\text { Lebar jalan } \\
\text { eksisting } \\
(\mathrm{m})\end{array}$ & $\begin{array}{l}\text { Penialai } \\
\text { an }\end{array}$ & Skor \\
\hline 1. & Asumanu & \multirow{3}{*}{$\begin{array}{l}40 / 60 \\
\mathrm{~m} / \mathrm{Ha} \text { lebar } \\
2-5 \mathrm{~m}\end{array}$} & \multirow[t]{3}{*}{576} & 352 & 3 & $61 \%$ & 3 \\
\hline 2. & Tohe & & & 245 & 3 & $43 \%$ & 3 \\
\hline 3. & Maumutin & & & 223 & 3 & $39 \%$ & 1 \\
\hline
\end{tabular}

Sumber : Hasil Analisa, 2019

Berdasarkan Tabel dan perhitungan di atas, maka diketahui bahwa penilaian ketersediaan panjang jalan yaitu Asumanu $61 \%$, Tohe $43 \%$ dan berdasarkan pada pedoman yang ada, apabila $40 \%-69 \%$ maka skor yang diberikan adalah 3 sedangkan untuk maunmutin 39\% dengan skor 1 atau $0 \%-39$ $\%$. Dari tabel di atas dapat diketahui bahwa total nilai tingkat ketersediaan jaringan Jalan di kawasan perbatasan adalah 3 dengan nilai rata-rata 3 atau dikategorikan sedang. b. Jaringan Air Bersih

Dalam kehidupan sehari-hari, air bersih merupakan kebutuhan wajib yang harus dipenuhi. Hampir semua kegiatan masyarakat menggunakan air bersih, tak terkecuali masyarakat di kawasan perbatasan. untuk mengetahui tingkat ketersediaan jaringan air bersih, maka digunakan metode perhitungan sebagai berikut :

Tabel 4 Hasil Analisis Ketersediaan Jaringan Air Bersih Kawasan Perbatasan Indonesia-Timor Leste

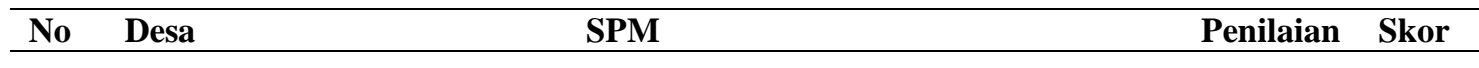




\begin{tabular}{|c|c|c|c|c|c|c|c|}
\hline & & $\begin{array}{l}\text { Tingkat } \\
\text { Pelayanan }\end{array}$ & Cakupan & $\begin{array}{l}\text { Penduduk } \\
\text { (Jiwa) }\end{array}$ & $\begin{array}{l}\text { Rumah } \\
\text { tangga }\end{array}$ & & \\
\hline 1. & Asumanu & \multirow{3}{*}{$\begin{array}{l}\text { Tersedia } \\
\text { layanan } \\
\text { pipa PDAM } \\
213 \mathrm{KK}\end{array}$} & \multirow{3}{*}{$\begin{array}{l}\text { Setiap } 1 \text { jiwa } \\
\text { membutuhkan } \\
60 \text { liter/hari }\end{array}$} & 1686 & 480 & $225 \%$ & 5 \\
\hline 2. & Tohe & & & 5213 & 1335 & $627 \%$ & 5 \\
\hline 3. & Maumutin & & & 3142 & 784 & $368 \%$ & 5 \\
\hline
\end{tabular}

Sumber : Hasil Analisa, 2019

Berdasarkan tabel dan perhitungan di atas, maka diketahui bahwa penilaian ketersediaan Jaringan Air bersih di kawasan perbatasan yaitu $100 \%$, dan berdasarkan pada pedoma yang ada, apabila $70 \%$ - $100 \%$ maka skor penilaian yang diberikan adalah 5

\section{c. Jaringan Drainase}

Jaringan drainase memiliki peranaan penting untuk mengalirkan air dari hulu ke hilir yang berfungsi lain untuk mencegah dan mengurangi terjadi banjir disuatu daerah.Sesuai dengan ketersedian panjang drainase di ketahui, bahwa panjang drainase di kawasan perbatasan dengan diikuti panjang jalan yang ada adalah masing-masing Desa Asumanu $352 \mathrm{~m}$, Desa Tobe $245 \mathrm{~m}$ dan Maumutin $223 \mathrm{~m}$, maka digunakan metode perhitungan sebagai berikut :

\section{d. Pengelolaan Limbah}

Pengelolaan limbah memiliki peranaan penting untuk mencegah pencemaran terhadap lingkungan. Sesuai dengan ketersedian kepemilikan MCK di ketahui bahwa
Tabel 5 Hasil Analisis Ketersediaan Jaringan Drainase Kawasan Perbatasan Indonesia-Timor Leste

\begin{tabular}{llll}
$\begin{array}{l}\text { Standar } \\
\text { SPM }\end{array}$ & $\begin{array}{l}\text { Jumlah } \\
\text { Ideal }\end{array}$ & Penilaian & Skor \\
\hline 2838 & 2838 & $12 \%$ & 1 \\
\cline { 3 - 4 } & & $9 \%$ & 1 \\
\cline { 2 - 3 } & & $8 \%$ & 1 \\
\hline
\end{tabular}

Sumber : Hasil Analisa, 2019

Berdasarkan Tabel dan perhitungan di atas, maka diketahui bahwa penilaian ketersediaan jaringan drainase yaitu 12\%, 9\% dan 8 Persen\%, dan berdasarkan pada pedoman yang ada, apabila $0 \%-39 \%$ maka skor yang diberikan adalah 1. Dari tabel di atas dapat diketahui bahwa total nilai tingkat ketersediaan jaringan Drainase di kawasan perbatasan adalah 1 dengan nilai rata-rata 1 atau dikategorikan Rendah.

kepemilikan kakus di kawasan perbatasan disesuaikan dengan rumah tangga dengan jumlah masing-masing desa $480 \mathrm{KK}, 1335$ KK, 784KK. untuk mengetahui tingkat ketersediaan pengelolaan limbah, maka digunakan metode perhitungan sebagai berikut

Tabel 6 Hasil Analisis Ketersediaan Pengelolaan Limbah

Kawasan Perbatasan Indonesia-Timor Leste

\begin{tabular}{|c|c|c|c|c|c|c|}
\hline No & Desa & Standar SPM & $\begin{array}{l}\text { Jumlah } \\
\text { Ideal }\end{array}$ & Ketersediaan & Penilaian & Skor \\
\hline 1. & Asumanu & \multirow{3}{*}{$\begin{array}{l}\text { Setiap } 84 \text { unit } \\
\text { rumah butuh } \\
84 \text { unit }\end{array}$} & \multirow[t]{3}{*}{84} & 480 & $571 \%$ & 5 \\
\hline 2. & Tohe & & & 1335 & $1589 \%$ & 5 \\
\hline 3. & Maumutin & & & 784 & $933 \%$ & 5 \\
\hline
\end{tabular}

Sumber : Hasil Analisa, 2019

Berdasarkan Tabel dan perhitungan di atas, maka diketahui bahwa penilaian ketersediaan pengelolaan limbah yaitu $100 \%$, dan berdasarkan pada pedoman yang ada, apabila $70 \%-100 \%$ maka skor yang diberikan adalah 5. Dari tabel di atas dapat diketahui bahwa total nilai tingkat ketersediaan MCK/kakus di kawasan perbatasan adalah 5 dengan nilai rata-rata 5 atau dikategorikan Tinggi.

\section{e. Sistem Persampahan}

Sistem persampahan di kawasan perbatasan seluruhnya dikelola sendiri dengan cara ditimbun atau dibakar. untuk mengetahui tingkat ketersediaan sistem persampahan, maka digunakan metode perhitungan sebagai berikut (tabel 7) 
Tabel 7 Hasil Analisis Ketersediaan Persampahan

Kawasan Perbatasan Indonesia-Timor Leste

\begin{tabular}{|c|c|c|c|c|c|c|c|}
\hline No & Desa & Uraian & $\begin{array}{l}\text { Standar } \\
\text { SPM }\end{array}$ & $\begin{array}{l}\text { Jumlah } \\
\text { Total }\end{array}$ & Ketersediaan & Penialaian & Skor \\
\hline 1. & Asumanu & \multirow{3}{*}{$\begin{array}{l}\text { Sistem } \\
\text { sarana } \\
\text { persampah } \\
\text { an }\end{array}$} & $\begin{array}{l}1 \text { orang } \\
11,6 \mathrm{lt} / \mathrm{KK}\end{array}$ & 213 tong & - & $0 \%$ & 1 \\
\hline 2. & Tohe & & $\begin{array}{l}1 \text { unit TPS } \\
\text { melayani } \\
\text { 40Lt/150 } \\
\text { KK }\end{array}$ & $1 \mathrm{TPS}$ & - & $0 \%$ & 1 \\
\hline \multirow[t]{2}{*}{3.} & Maumutin & & $\begin{array}{l}\mathrm{Lt} / 150 \mathrm{KK} \\
1 \mathrm{TPS}-0 \% \\
1 \text { unit } \\
\text { gerobak } \\
\text { sampah } \\
\text { melayani } \\
10001 \mathrm{t} / 200 \\
\mathrm{KK}\end{array}$ & $\begin{array}{l}1 \text { unit } \\
\text { gerobak }\end{array}$ & - & $0 \%$ & 1 \\
\hline & & $\begin{array}{l}\text { Sistem } \\
\text { pengangku } \\
\text { tan sampah }\end{array}$ & $\begin{array}{l}\text { Pengambil } \\
\text { an sampah } \\
1 \text { minggu } 3 \\
\text { kali }\end{array}$ & $\begin{array}{l}\text { Pengambil } \\
\text { an sampah } \\
1 \text { minggu } 3 \\
\text { kali }\end{array}$ & $\begin{array}{l}\text { Masih bersifat } \\
\text { individu \& } \\
\text { belum } \\
\text { dilakukan } \\
\text { pengangkutan } \\
\text { sampah }\end{array}$ & $0 \%$ & 1 \\
\hline
\end{tabular}

Sumber : Hasil Analisa, 2019

Berdasarkan tabel dan perhitungan di atas, maka diketahui bahwa persentase ketersediaan sistem sarana persampahan untuk tong sampah $0 \%$, dan berdasarkan pada pedoman yang ada, apabila $0 \quad \% \quad-39,99 \%$ maka skor yang diberikan adalah 1 . TPS sebanyak $0 \%$, dan berdasarkan pada pedoman yang ada, $0 \%$ $39,99 \%$ maka skor yang diberikan adalah 1 . Gerobak sampah $0 \%$, dan berdasarkan pada pedoman yang ada, apabila $0 \%-39,99 \%$ maka skor yang diberikan adalah 1 . sedangkan untuk sistem pengolahan dan pengangkutan sampah sebesar $100 \%$, dan berdasarkan pada pedoman yang ada, apabila $0 \%-39,99 \%$ maka skor yang diberikan adalah 1 Dari tabel di atas dapat diketahui bahwa total nilai tingkat ketersediaan Sistem persampahan di kawasan perbatasan dengan nilai rata-rata 1 atau dikategorikan rendah.

\section{Analisis Tingkat pelayanan Infrastruktur Kawasan Perbatasan}

a. Jalan

Jalan merupakan salah satu infrastruktur pendukung dalam mengembangkan suatu wilayah.Semakin baik kondisi jalan,,maka semakin muda bagi masyarakat untuk mengakses tempat suatu wilayah tersebut.Berdasarkan hasil pengamatan secara langsung yang dilakukan, bahwa sudah tersedia akses jalan disana namun kondisi jalan yang masih buruk karena belum ada perbaikan. Adapun dapat di lihat pada tabel berikut:

Tabel 8 Analisa Kondisi Jalan

\begin{tabular}{lllllllllll}
\hline \multirow{2}{*}{ No Desa } & \multicolumn{3}{c}{ Jenis Jalan } & \multicolumn{3}{c}{ Kebutuhan } & \multicolumn{2}{c}{ Perlu Diperbaiki } \\
\cline { 3 - 12 } & & Aspal & Tanah & Lainnya & Kurang & Cukup & $\begin{array}{l}\text { Sangat } \\
\text { cukup }\end{array}$ & Perlu & $\begin{array}{l}\text { Cukup } \\
\text { Perlu }\end{array}$ & $\begin{array}{l}\text { Tidak } \\
\text { Perlu }\end{array}$ \\
\hline 1. & Asumanu & 11 & 19 & 3 & 33 & 0 & 0 & 33 & 0 & 0 \\
\hline 2. & Tohe & 21 & 8 & 4 & 25 & 8 & 0 & 28 & 5 & 0 \\
\hline 3. & Maumutin & 9 & 22 & 2 & 29 & 4 & 0 & 31 & 2 & 0 \\
\hline & Jumlah & 41 & 49 & 9 & 87 & 12 & 0 & 92 & 7 & 0 \\
\hline & $\%$ & 0,41 & 0,49 & 0 & 0,88 & 0,12 & 0 & 0,93 & 0,07 & 0 \\
\hline
\end{tabular}


Dari tabel diatas yang dihimpun dari pendapat masyarakat melalui kuisioner maka untuk Infrastruktur berupa Jalanyang menghubungkan atar wilayah dan kegiatan masih berupa Jalan Tanah dengan presentase sebesar $49 \%$. Untuk Kondisi jalan yang djaring dari kuisioner terlihat bahwa masih sangat kurang dengan persentase $88 \%$. Untuk perbaikan jalan yang di himpun dari masyarakat menjawab perlu di perbaiki dengan persentase $93 \%$

\section{b. Jembatan}

Jembatan berfungsi sebagai penghubung dua bagian jalan yang terputus akibat beberapa kondisi yang dipisakan oleh sungai,dan lain sebagainya. Berdasarkan hasil pengamatan di lokasi penelitian kondisi jembatan yang ada di sana belum begitu bagus dan masih rusak karena belum ada perbaikan.

Tabel 9 Analisa Kondisi Jembatan

\begin{tabular}{lllllllllll}
\hline \multirow{2}{*}{ No } & Desa & \multicolumn{4}{c}{ Jenis } & \multicolumn{3}{c}{ Kebutuhan } & \multicolumn{2}{c}{ Perlu Diperbaiki } \\
\cline { 3 - 11 } & & Kayu & Semen & Lainnya & Kurang & Cukup & $\begin{array}{l}\text { Sangat } \\
\text { cukup }\end{array}$ & Perlu & $\begin{array}{l}\text { Cukup } \\
\text { Perlu }\end{array}$ & $\begin{array}{l}\text { Tidak } \\
\text { Perlu }\end{array}$ \\
\hline 1. & Asumanu & 0 & 28 & 5 & 6 & 27 & 0 & 28 & 5 & 0 \\
\hline 2. & Tohe & 0 & 30 & 3 & 10 & 23 & 0 & 29 & 4 & 0 \\
\hline 3. & Maumutin & 0 & 27 & 6 & 21 & 12 & 0 & 25 & 8 & 0 \\
\hline & Jumlah & $\mathbf{0}$ & $\mathbf{8 5}$ & $\mathbf{1 4}$ & $\mathbf{3 7}$ & $\mathbf{6 2}$ & $\mathbf{0}$ & $\mathbf{8 2}$ & $\mathbf{1 7}$ & $\mathbf{0}$ \\
\hline & $\%$ & $\mathbf{0}$ & $\mathbf{0 , 8 6}$ & $\mathbf{0 , 1 4}$ & $\mathbf{0 , 3 7}$ & $\mathbf{0 , 6 3}$ & $\mathbf{0}$ & $\mathbf{0 , 8 3}$ & $\mathbf{0 , 1 7}$ & $\mathbf{0}$ \\
\hline
\end{tabular}

Sumber: Hasil Kuesioner dan Analisis, 2019

Dari tabel diatas yang dihimpun dari pendapat masyarakat melalui kuisioner maka untuk Infrastruktur berupa Jembatan yang menghubungkan antar wilayah dan kegiatan masih berupa semen dengan presentase sebesar $85 \%$. Untuk Kondisi jembatan yang dijaring dari kuisioner terlihat bahwa masih sangat kurang dengan persentase $63 \%$. Untuk perbaikan dan perawatan jembatan yang di himpun dari masyarakat menjawab perlu di perbaiki dengan persentase $83 \%$.

\section{c. Komunikasi}

Jaringan telekomunikasi di lokasi penelitian sudah cukup baik dengan sudah tersedia beberapa BTS telkomsel di setiap desa dengan jenis jaringan 4G. Jumlah BTS di masing-masing Desa berjumlah 3 .

Tabel 10 Analisa Kondisi Jaringan Telekomunikasi

\begin{tabular}{|c|c|c|c|c|c|c|c|c|c|c|c|}
\hline \multirow[t]{2}{*}{ No } & \multirow[t]{2}{*}{ Desa } & \multirow{2}{*}{$\begin{array}{c}\text { Jumlah } \\
\text { BTS }\end{array}$} & \multicolumn{3}{|c|}{ Jenis Telekomonikasi } & \multicolumn{3}{|c|}{ Kebutuhan } & \multicolumn{3}{|c|}{ Perlu Diperbaiki } \\
\hline & & & BTS & STO & Lainnya & Kurang & Cukup & $\begin{array}{l}\text { Sangat } \\
\text { cukup }\end{array}$ & Perlu & $\begin{array}{l}\text { Cukup } \\
\text { Perlu }\end{array}$ & $\begin{array}{l}\text { Tidak } \\
\text { Perlu }\end{array}$ \\
\hline 1. & Asumanu & 1 & 33 & 0 & 0 & 6 & 27 & 0 & 30 & 5 & 0 \\
\hline 2. & Tohe & 1 & 33 & 0 & 0 & 3 & 30 & 0 & 27 & 6 & 0 \\
\hline 3. & Maumutin & 1 & 33 & 0 & 0 & 5 & 28 & 0 & 24 & 9 & 0 \\
\hline & Jumlah & 3 & 99 & $\mathbf{0}$ & $\mathbf{0}$ & 14 & 85 & $\mathbf{0}$ & 81 & 18 & $\mathbf{0}$ \\
\hline & $\%$ & & 1 & $\mathbf{0}$ & $\mathbf{0}$ & 0,24 & $\mathbf{0 , 8 6}$ & $\mathbf{0}$ & $\mathbf{0 , 8 2}$ & $\mathbf{0 , 1 8}$ & $\mathbf{0}$ \\
\hline
\end{tabular}

Sumber: Hasil Kuesioner dan Analisis, 2019

Dari tabel diatas yang dihimpun dari pendapat masyarakat melalui kuisioner maka untuk jaringan berupa telekomunikasi tesedia BTS sudah cukup terlayani semua dengan persentase $99 \%$. Untuk Kondisi jaringan telekominikasi kuisioner terlihat bahwa Sudah cukup dengan persentase $86 \%$. Untuk perbaikan atau perawatan yang di himpun dari masyarakat menjawab perlu di perbaiki dengan persentase $82 \%$. 


\section{d. Jaringan Air Bersih}

Air bersih menjadi kebutuhan untuma masyarakat di mana air bersih dapat digunakan untuk mencuci,memasak mandi,dan sebagainya. Tersedianya air bersih di lokasi studi sundah sangat memadai hal ini di karenakan sumber air yang di pakai,langsung dari titik mata air di bawah kaki gunung ke kawasan permukiman masyarakat setempat,dan pihak setempat menyediakan tiap viber di setiap tempat dan minimal satu viber di sediakan untuk 20 samapai 25 rumah tangga.

Tabel 11 Jenis Jaringan Air Bersih

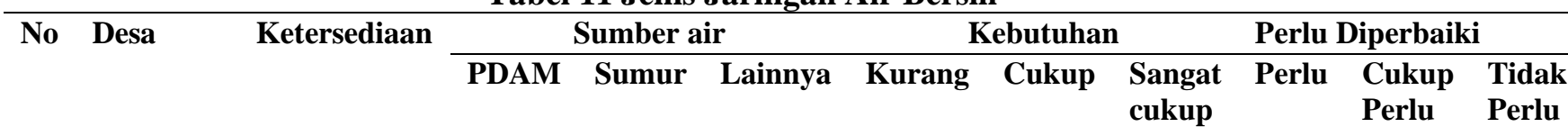

\begin{tabular}{llllllllllll}
\hline 1. & Asumanu & 1 & 0 & 5 & 28 & 28 & 5 & 0 & 30 & 3 & 0 \\
\hline 2. & Tohe & 1 & 0 & 0 & 33 & 0 & 28 & 5 & 31 & 2 & 0 \\
\hline 3. & Maumutin & 1 & 0 & 6 & 27 & 0 & 29 & 4 & 28 & 5 & 0 \\
& & & & & & & & & & \\
\hline & Jumlah & $\mathbf{3}$ & $\mathbf{0}$ & $\mathbf{1 1}$ & $\mathbf{8 8}$ & $\mathbf{2 8}$ & $\mathbf{6 2}$ & $\mathbf{9}$ & $\mathbf{8 9}$ & $\mathbf{1 0}$ & $\mathbf{0}$ \\
\hline & $\mathbf{0}$ & & $\mathbf{1}$ & $\mathbf{0 , 1 1}$ & $\mathbf{0 , 8 9}$ & $\mathbf{0 , 2 8}$ & $\mathbf{0 , 6 3}$ & $\mathbf{0 , 9 9}$ & $\mathbf{0 , 9}$ & $\mathbf{0 , 1}$ & $\mathbf{0}$
\end{tabular}

Sumber: Hasil Kuesioner dan Analisis, 2019

Dari tabel diatas yang dihimpun dari pendapat masyarakat melalui kuisioner maka untuk sumber air bersih dari titik mata air dengan presentase sebesar $89 \%$. Untuk kebutuhan yang dijaring dari kuisioner terlihat bahwa Sudah sedikit cukup dengan persentase $63 \%$. Untuk perbaikan perbaikan atau perawatan yang di himpun dari masyarakat menjawab perlu di perbaiki dengan persentase $90 \%$.

\section{e. Pengolahan Sampah}

Untuk limbah padatnya masyarakat di lokasi penelitian atau sebagian besar masyarakat kecamatan Raihat tidak di siapkan kotak sampah atau tempat pengolahan sehingga masyarakat langsung menggumpulkan sendiri dan dibakar dan juga tidak ada limbah berbahaya beracun, berbahaya,berbau (B3) karena kebanyakan sampah yang ada hanya kertas dan plastikplastik bekas

Tabel 12Analisa Pengolahan Sampah

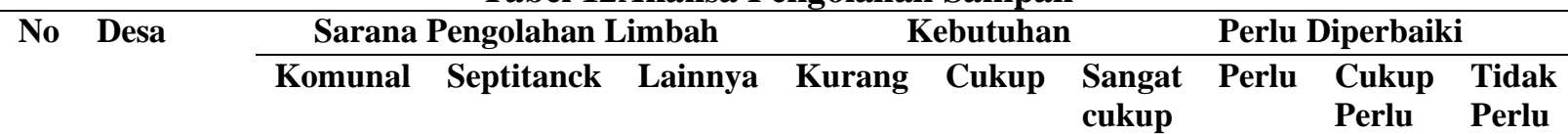

\begin{tabular}{lllllllllll}
\hline 1. & Asumanu & 2 & 20 & 11 & 28 & 3 & 2 & 30 & 0 & 3 \\
\hline 2. & Tohe & 5 & 26 & 2 & 21 & 9 & 3 & 25 & 7 & 1 \\
\hline 3. & Maumutin & 0 & 29 & 4 & 24 & 7 & 2 & 19 & 1 & 13 \\
& & & & & & & & & \\
\hline & Jumlah & $\mathbf{7}$ & $\mathbf{7 5}$ & $\mathbf{1 7}$ & $\mathbf{7 3}$ & $\mathbf{1 9}$ & $\mathbf{7}$ & $\mathbf{7 4}$ & $\mathbf{8}$ & $\mathbf{1 7}$ \\
\hline & $\mathbf{0}$ & $\mathbf{0 , 0 7}$ & $\mathbf{0 , 7 6}$ & $\mathbf{0 , 1 7}$ & $\mathbf{0 , 7 4}$ & $\mathbf{0 , 1 9}$ & $\mathbf{0 , 0 7}$ & $\mathbf{0 , 7 5}$ & $\mathbf{0 , 0 8}$ & $\mathbf{0 , 1 7}$ \\
\hline
\end{tabular}

Sumber: Hasil Kuesioner dan Analisis, 2019

Dari tabel diatas yang dihimpun dari pendapat masyarakat melalui kuisioner maka untuk jaringan pengolahan limbah padat dan cair lebih banyak menggunakan septi tank dengan presentase sebesar $76 \%$. Untuk kebutuhan yang dijaring dari kuisioner terlihat bahwa masih sangat kurang dengan persentase
74\%. Untuk perbaikan dan perawatan atau perbaikan yang di himpun dari masyarakat menjawab perlu di perbaiki dengan persentase $75 \%$ 
f. Jaringan Listrik

Untuk pelayann jaringan listrik sendiri di lokasi sudah cukup terlayani karena sumber jaringan listrik langsung di tarik dari PLN Atambua pusat kabupaten Belu menuju ke daerah perbatasan atau lokasi penelitian.

Tabel 13 Analisa jaringan listrik

\begin{tabular}{|c|c|c|c|c|c|c|c|}
\hline No & Desa & Uraian & $\begin{array}{l}\text { Standar } \\
\text { SPM }\end{array}$ & $\begin{array}{l}\text { Jumlah } \\
\text { Total }\end{array}$ & Ketersediaan & Penialaian & Skor \\
\hline 1. & Asumanu & \multirow{3}{*}{$\begin{array}{l}40 / 60 \\
\mathrm{~m} / \mathrm{Ha} \text { lebar } \\
2-5 \mathrm{~m}\end{array}$} & \multirow[t]{3}{*}{576} & 352 & 3 & $61 \%$ & 3 \\
\hline 2. & Tohe & & & 245 & 3 & $43 \%$ & 3 \\
\hline 3. & Maumutin & & & 223 & 3 & $39 \%$ & 1 \\
\hline
\end{tabular}

Sumber: Hasil Kuesioner dan Analisis, 2019

Dari tabel diatas yang dihimpun dari pendapat masyarakat melalui kuisioner maka untuk sumber jaringan listrik lebih banyak menggunakan sumber PLN dengan presentase sebesar $87 \%$. Untuk kebutuhan jaringan listrik

\section{KESIMPULAN}

Dari hasil analisa yang dilakukan, Diketahui kondisi dan tingkat pelayanan infrastruktur di kawasan perbatasan Indonesia dan Timor Leste, Dimana Desa Asumanu,Tohe dan Maumutin yang menjadi fokus dalam penelitian ini perlu adanya kebutuhan jalan, jembatan, telekominikasi air bersih,penggolahan limbah dan jaringan listrik. Untuk kebutuhan jalan sendiri berdasarkan hasil analisa masih banyak terdapat jalan tanah yang masih sangat kurang untuk kebutuhan masyarakat perbatasan dimana jalan merupakan sarana penghubung dari 1 tempat ke tempat lain, Maka perlu di perbaiki kebutuhan jalan agar sesuai dengan standar yang ada. Jembatan yang ada di 3 desa penelitian merupakan jembatan yang menghubungkan antara desa kecamatan dan lintas Negara sebagai tingat pelayanan infrastruktur yang ada dimana kondisi jembatan perlu diperbaiki karena tidak memenuhi standar sebab jembatan yang ada merupakan jenis jembatan semen, perlu perbaikan perkerasan dan pelebaran jembatan agar dapat melayani tingkat aktivitas yang menggunakan. Telekomunikasi merupakan sarana yang menghubungkan dan memudahakan dalam pemasaran dan pemerintahan tetapi di kondisi eksisting yang dijaring dari kuisioner terlihat bahwa Sudah cukup dengan persentase $75 \%$. Untuk perbaikan perbaikan atau perawatan yang di himpun dari masyarakat menjawab perlu di perbaiki dengan presentasi $84 \%$.

yang ada penyedian BTS untuk melayani masih belum sesuai dengan standar dan tingkat pelayanaan yang sesuai,sebab masih membutuhkan penambahan BTS dan STO untuk meningkatkan kebutuhan jaringan telekomunikasi dengan baik di lokasi penelitian. Air bersih merupakan kebutuhan utama sehari-hari unruk minum,memasak,mencuci,mandi,dan sebagainya. Dari hasil analisa yang dilakukan perlu adanya peningkatan perbaikan dan penyediaan untuk memenuhi kebutuhan sebab kondisi yang sekarang air bersih masih belum terlayani dengan baik karena sebagian masyarakat masih mengmbil air jauh dari tempat tinggal atau permukiman warga akibat kekeringan hal ini menjadi masalah untuk mengatasi agar dapat terlayani dengan kebutuhan pipa,viber untuk sampai ke kawasan permukiman warga. Penggolahan limbah merupakan sarana yang mempegaruri lingkugan agar tidak terjadi pecemaran,berdasarkan hasil anilisa yang dilakukan masih belum tersedianya TPA dan TPS di tempat,hal ini membuat penggolahan limbah tidak teratur dan juga masyarakat membuang sampah sembarangan yang mengakibatkan pencemaran lingkungan di sekitar,maka dari hasil analisa ini perlu di sediakan TPS dan TPA di setiap rumah dan tempat umum agar masyarakat dapat membuang sampah pada tempatnya. Sedangkat 
kebutuhan listrik dari hasil analisa sudah terlayani semua dengan baik namun hanya beberapa yang belum terlayani akibat lokasi yang jauh dari permukiman dan jarak medan yang tidak memungkinkan,hal ini perlu diatasi agara semua masyarakat di desa dapat terlayani semua sesui dengan standar kebutuhan yang ada.

\section{UCAPAN TERIMAKASIH}

Penulis mengucapkan terimakasih kepada Jurusan Perencanaan Wilayah dan Kota di ITN, Malang.

\section{REFERENSI}

Adl-Zarrabi, Bijan. (2017). What is 'Infrastructure Physics?. The 15th International Symposium on District Heating and Cooling. Energy Procedia (52), 132-520

Arikunto, Suharsimi. (2010). Prosedur Penelitian Suatu Pendekatan Praktik. Yogyakarta: Rineka Cipta.

Avritzer, Alberto, dkk. (2015). Survivability Evaluation of Gas, Water and Electricity Infrastructures. Electronic Notes in Theoretical Computer Science (310),5-25.

Darmawansyah. (2017). Studi Ketersediaan Dan Kebutuhan Infrastruktur Kawasan Permukiman Kumuh Kota Pangkajene Kabupaten Pangkep (Skripsi). Retrieved from http://repositori.uinalauddin.ac.id/6974/1/Darmawansyah\%2 Cpdf.pdf

Grigg, N. (1998). Infrastructure Engineering and Management. New York: John Wiley $\&$ Sons.

Muradi. (2015). Pengelolaan pengamanan perbatasan indonesia. Jurnal Ilmu Pemerintahan, 1(1), 25-34.

Tokunova, Galina. (2018). Assessment of the transport infrastructure influence on urban agglomerations development. Thirteenth
International Conference on Organization and Traffic Safety Management in Large Cities. Transportation Research Procedia $36754-758$.

Purnamasari, Wulan., Muslimin H. Kara,., Moh. Sabri AR , Amiruddin, K. (2016.). Perkembangan Pembangunan Ekonomi Kawasan Perbatasan Negara Indonesia Malaysia Di Sambas. Jurnal Diskursus Islam, 4(2), 217-247.

Sari, U.C.,\& Rahman, Boby. (2019). Studi Literatur: Kajian Geoteknik Daerah Perbatasan Sebagai Salah Satu Faktor Dalam Penguatan Infrastruktur Daerah Perbatasan Di Kabupaten Belu, Nusa Tenggara Timur. Jurnal Planologi, 16(1), 32-44.

Skorobogatova, Oksana \& Irina KuzminaMerlino. (2017). Transport Infrastructure Development Performance. Conference on Reliability and Statistics in Transportation and Communication. Procedia Engineering $178319-329$.

Sudiar, S. (2017). Pembangunan Wilayah Perbatasan Negara: Gambaran Tentang Strategi Pengelolaan Kawasan Perbatasan Darat Di Provinsi Kalimantan Utara. Jurnal Administrative Reform (JAR), 3(4), 489-500.

Sugiyono. (2013). Metode Penelitian Kuantitatif, Kualitatif dan $R \& D$. Bandung: Alfabeta.

Nugroho, S.P. 2010. Pengaruh Pertumbuhan Ekonomi Pendapatan Asli Daerah, dan Dana Alokasi Umum Tehadap Pengalokasian Anggaran Belanjan Modal (Skripsi). Retrieved from http://eprints.undip.ac.id/26411/1/skripsi. pdf

Warsilan., \& Akhmad Noor. (2015). Peranan Infrastruktur terhadap Pertumbuhan Ekonomi dan Implikasi pada Kebijakan Pembangunan di Kota Samarinda. MIMBAR, 31(2), 359-366. 